\title{
DOES TALKING TO THE OTHER SIDE REDUCE INTER-PARTY HOSTILITY? \\ EVIDENCE FROM THREE STUDIES
}

Eran Amsalem

Department of Communication

Hebrew University of Jerusalem

eran.amsalem@mail.huji.ac.il

Eric Merkley

Munk School of Global Affairs \& Public Policy

University of Toronto

eric.merkley@utoronto.ca

Peter John Loewen

Munk School of Global Affairs \& Public Policy

University of Toronto

peter.loewen@utoronto.ca

*Address correspondence to Eran Amsalem, Department of Communication, Hebrew University of Jerusalem, Mt. Scopus, Jerusalem 91905, Israel; email: eran.amsalem@mail.huji.ac.il

Forthcoming in Political Communication 


\title{
DOES TALKING TO THE OTHER SIDE REDUCE INTER-PARTY HOSTILITY? EVIDENCE FROM THREE STUDIES
}

\begin{abstract}
According to recent scholarship, citizens in various Western democracies show a growing sense of dislike and distrust toward members of opposing political parties. While political communication processes have been shown to influence inter-party hostility, the literature has so far focused mainly on mass-mediated communication. We argue here that affective polarization might also be determined by interpersonal political communication. Specifically, we hypothesize that "heterogeneous" political discussions - those transcending partisan and ideological boundaries - are associated with decreased hostility toward the other side. We test this hypothesis with three studies conducted in Canada: A cross-sectional survey $(N=3,596)$, a twowave panel $(N=3,408)$, and an instrumental variable analysis $(N=2,005)$. We find that heterogeneous discussion indeed is associated with reduced polarization, a conclusion that holds across indicators of affect, obtains for both face-to-face and online discussions, and is consistent across studies. Having a heterogeneous (compared to homogeneous) discussion network predicts substantial decreases of up to 0.76 , and no less than 0.09 , standard deviations in out-party hostility. These findings inform scholarly debates about the antecedents of affective polarization and are consistent with the claim that cross-cutting political discussion can benefit democracy.
\end{abstract}

Keywords: affective polarization; interpersonal communication; political discussion; peer networks; intergroup contact 
Affective polarization is on the rise. There is growing evidence that supporters of political parties increasingly dislike and distrust political elites and supporters from opposing parties (Iyengar et al., 2012, 2019; Druckman \& Levendusky, 2019). While evidence of affective polarization comes mainly from the US, an emerging comparative research agenda suggests that this process has also occurred in other Western democracies like Canada (e.g., Boxell et al., 2020b; Cochrane, 2015; Gidron et al., 2020).

In recent years, the literature has proposed not only descriptive analyses of trends in affective polarization but also explanatory tests of the antecedents of this phenomenon (for a review, see Iyengar et al., 2019). Among other explanations, past research has consistently indicated that political communication processes can influence inter-party hostility. So far, most scholarly attention has been devoted to mass-mediated forms of communication, such as partisan cable news (e.g., Levendusky, 2013) or information consumption on the internet (e.g., Lelkes et al., 2017). Yet we know from a large literature that citizens' political attitudes are also shaped through interpersonal communication. In the course of their daily lives, people discuss politics with their family members, friends, co-workers, and others, and these conversations often have strong effects on their attitudes (Huckfeldt et al., 2004; Katz \& Lazarsfeld, 1955; Mutz, 2002).

In the current study, we explore the relationship between political discussion and affective polarization. Our substantive focus is on the composition of people's discussion networks. Past research has repeatedly demonstrated that "heterogeneous" political discussions, in which people talk to others who hold different political views and support different political parties from their own, have largely positive implications for democracy (e.g., Mutz, 2002; Nir, 2017). In the more specific context of polarization, heterogeneous discussion has been associated with less polarized policy attitudes (Druckman et al., 2018; Huckfeldt \& Sprague, 1995) and 
candidate evaluations (Huckfeldt et al., 2004; Hutchens et al., 2019). However, the relationship between heterogeneous political discussion and outgroup evaluations more broadly has not been fully clarified.

Drawing theoretically on the interpersonal communication literature, we hypothesize that heterogeneous political discussion is negatively associated with hostility toward political outgroups. In other words, we expect talking about politics with non-like-minded others to have a depolarizing effect on the electorate. We test this hypothesis with three complementary studies. First, we use data from cross-sectional surveys conducted during the 2019 federal election campaign in Canada $(N=3,596)$. Second, we report on a two-wave panel study $(N=3,408)$ conducted in Canada between March and May of 2020. The panel allows us to evaluate the overtime effects of political discussion networks (Sinclair, 2012). Third, we address potential endogeneity between discussion heterogeneity and affective polarization with an instrumental variable analysis using survey data collected in Canada in early $2021(N=2,005)$. We find that heterogeneous political discussion predicts substantial reductions in affective polarization. This conclusion holds across indicators of affect, across contexts of political discussion (i.e., both face-to-face and online), and across samples.

\section{Affective Polarization}

One of the critical findings of American public opinion research over the past decade has been the growing affective gulf between supporters of the Republican and Democratic parties, known as affective polarization. Supporters of the two major parties increasingly dislike outparty political elites and supporters (Druckman \& Levendusky, 2019; Iyengar et al., 2012). Recent research has extended this agenda cross-nationally, finding evidence of affective polarization in other countries (Boxell et al., 2020b; Gidron et al., 2020). In Canada, we see 
strong evidence of an affective polarization process where Conservative partisans increasingly dislike the Liberal Party, while Liberal and NDP partisans increasingly dislike the Conservative Party and become warmer to one another (Cochrane, 2015; Johnston, 2019; Merkley, 2020).

Understanding the antecedents of affective polarization is vitally important. Scholars have shown it to have negative implications for the public's trust in government and institutions (Hetherington \& Rudolph, 2015) and to influence economic perceptions and behavior (Healy \& Malhotra, 2013). Out-party animus can also spill over into individuals' social interactions by influencing their willingness to engage in relationships with out-party supporters (Iyengar et al., 2012) and tendency to discriminate against out-partisans (Sheffer, 2020).

And yet, the causes of affective polarization are still heavily contested. Some argue that it is the result of social sorting where ideological, partisan, and social identities come into closer alignment (Mason, 2016). Others see elite ideological polarization as the driving influence (Rogowski \& Sutherland, 2016), a finding that has some support in Canada as well (Johnston, 2019). A different line of research, on which we build here, focuses on the role of political communication. Most studies in this literature examine the effects of mass-mediated communication on affective polarization (e.g., Levendusky, 2013; Tsfati \& Nir, 2017). Here, we explore the role of interpersonal communication.

\section{Heterogeneous Political Discussion}

Our investigation is motivated by the assumption that one's political information environment matters a great deal for polarization (Iyengar et al., 2019). Yet, while massmediated communication has been associated in a host of studies with affective polarization, the role of interpersonal communication remains understudied. We examine the possibility that the 
partisan and ideological composition of people's discussion network is linked to their affective evaluations of political outgroups.

The idea that interpersonal communication shapes citizens' political attitudes is not a new one. Landmark studies in the discipline have shown that informal conversations with those comprising one's social network—friends, neighbors, co-workers, and the like—can strongly influence political opinions and decisions (e.g., Katz \& Lazarsfeld, 1955; Lazarsfeld et al., 1948). A great deal of more recent scholarship has confirmed the importance of political discussion. Within this large literature, numerous studies have investigated the effects of crosscutting or heterogeneous discussions, whereby people talk about politics to others with divergent party attachments or ideological beliefs (Huckfeldt et al., 2004; Nir, 2017).

Over the past two decades, researchers have uncovered a variety of positive consequences of heterogeneous discussion for democracy. For example, it increases political tolerance by allowing people to learn about legitimate rationales for oppositional viewpoints (Mutz, 2002); promotes participation in politics by fostering media use (Scheufele et al., 2004); and enhances factual political knowledge by exposing people to information they were not aware of (Amsalem \& Nir, 2021). Despite the richness of evidence on the democratic consequences of heterogeneous political discussion, research into its relationship with affective polarization—one of the most important phenomena in current politics—is limited in scope.

\section{Discussion Heterogeneity and Affective Polarization}

We expect discussion heterogeneity to be associated with decreased affective polarization for two theoretical reasons: the information political discussions provide, and their impact on the salience of political identities. The informational perspective we propose is based on the wellestablished finding that the social networks people are embedded in serve as important channels 
through which they gain political information (Eveland \& Hively, 2009; Huckfeldt et al., 2004; Huckfeldt \& Sprague, 1995). In the context of affective polarization, prior work suggests that the information voters hold about the political outgroup shapes their affective evaluation of it. For example, Ahler and Sood (2018) find that misperceptions of the extent to which party supporters belong to party-stereotypical groups increase outgroup dislike. Other research finds that partisans who overestimate the ideological differences between the political parties show greater interparty animosity (Wilson et al., 2020).

When political conversations occur in a homogeneous setting, consisting mainly (or only) of co-partisans and co-ideologues, the information people get exposed to is likely to be strongly skewed in favor of the ingroup and against the outgroup (Druckman et al., 2018). If this information was already known to discussion participants, repeating it can increase its salience in people's minds and, therefore, its influence on overall judgments of the outgroup (Zaller, 1992). If the pieces of information were unknown to discussion participants, they can serve as persuasive arguments against the outgroup (Druckman et al., 2018; Sunstein, 2002). In fact, even when they get exposed to counter-attitudinal information, partisans in a homogeneous network are likely to dismiss it by engaging in partisan-motivated reasoning (Klar, 2014). In contrast, individuals in heterogeneous networks get exposed during discussions to a more balanced set of messages. As a result, the attitudes they develop toward the outgroup incorporate both positive and negative assessments and thus become more ambivalent, and less polarized (Huckfeldt et al., 2004). Individuals in heterogeneous networks are also less likely to engage in partisan-motivated reasoning than people in homogeneous networks (Klar, 2014).

The second theoretical consideration relevant to anticipating the effect of heterogeneous discussion on affective polarization is the impact political conversations have on the salience of 
partisan identity (Iyengar et al., 2012). When membership in a social or political group is made salient in people's minds, they tend to adopt attitudes and behaviors that are congruent with the identity that has been activated (Spears, 2011). One way in which such activation of partisan identity occurs is through political discussion in a homogeneous network (Levendusky et al., 2016; Parsons, 2015; Sinclair, 2012). Heightened salience of partisan identity, in turn, facilitates cognitive processes that are likely to exacerbate polarization, such as thinking about politics in terms of "us" versus "them," seeking to be prototypical ingroup members by displaying behaviors that are clearly distinguished from those of the outgroup, and engaging in partisanmotivated reasoning (Hutchens et al., 2019; Klar, 2014; Suhay, 2015).

Our expectation of a negative relationship between heterogeneous discussion and affective polarization is supported by two prominent streams of research. The first is the extensive group polarization literature from social psychology. This line of research demonstrates, across many different contexts, that the modal outcome of group discussion is an enhancement of the initial tendency of group members. The polarizing influence of group discussion, this literature finds, is driven by both exposure to new information (Sunstein, 2002) and increased salience of group identity (Spears et al., 1990).

The second supportive line of research is intergroup contact theory. Studies consistently find that interaction with members of the political outgroup — both face-to-face and onlinechallenges stereotypes that develop in the absence of intergroup contact and increases the willingness to compromise with the outgroup (Bond et al., 2018; Wojcieszak \& Warner, 2020). Applied to our context, inter-party conversations should reduce outgroup hostility by allowing partisans to (a) see each other as individuals rather than out-party prototypes (Rossiter, 2020) and (b) identify commonalities with the outgroup (Wojcieszak \& Warner, 2020). 
Based on the theoretical perspectives described above, we make the following prediction:

H1: There is a negative relationship between face-to-face heterogeneous political discussion and affective polarization.

The majority of research on political discussion networks examines various forms of face-to-face communication, such as the workplace, the family, or interactions with close friends (e.g., Mutz, 2002). While face-to-face political conversations still exert substantial influences on political behavior (e.g., Druckman et al., 2018), in the past two decades or so, the internet has become an increasingly popular medium for political discussions (Baek et al., 2012). Acknowledging this significant development, scholars have begun in recent years to explore the nature and effects of online discussion. This literature, however, is still underdeveloped. As was recently noted by Tucker et al. (2018), compared to face-to-face discussion, there is much less research estimating the proportion of online political conversations that occur across partisan boundaries, and few studies compare the effects of online and face-to-face conversations.

We expect online discussion heterogeneity to also be negatively related to affective polarization. In terms of our first theoretical explanation (i.e., the informational effects of political discussions), numerous studies have shown that exposure to attitude-consistent political content on the internet results in stronger and more polarized political attitudes, whereas attitudediscrepant online content leads to depolarized, more ambivalent attitudes (Tsfati \& Nir, 2017; Settle, 2018). One explanation for this depolarizing effect is that online communication, particularly on social media, exposes people to diverse perspectives to which they would not be exposed otherwise in their face-to-face interactions (Barberá, 2015).

Past research also provides reasons to expect our second theoretical explanation (i.e., the impact of political discussions on the salience of partisan identity) to be relevant in the online 
sphere. Studying the way citizens communicate about politics on Facebook, Settle (2018) argues that the defining elements of this platform, which include constant activation of social and political identities, are "uniquely suited to facilitate psychological processes of polarization" (Settle, 2018, pp. 7-8). Indeed, Settle (2018) finds that social media communication strongly activates political identities, thus increasing stereotyping of, and negative affect toward, outpartisans. Other studies have documented identity-enhancing dynamics in additional contexts of online political communication, such as political blogs (Lawrence et al., 2010) and Twitter (Yardi \& Boyd, 2010).

Based on these theoretical considerations, we expect the following:

H2: There is a negative relationship between online heterogeneous political discussion and affective polarization.

How does the impact of online discussion on affective polarization compare with that of face-to-face discussion? On the one hand, online conversations may have stronger effects because they allow for anonymity (Spears et al., 1990) and are often uncivil (Rossini, 2020)characteristics that exacerbate affective polarization (e.g., Skytte, 2020). On the other hand, online discussion may have weaker effects: online, many of people's discussion partners are individuals with whom they have weak social ties (Barberá, 2015; Settle, 2018), whereas face-toface discussions mainly feature close others, such as friends and family members (Huckfeldt \& Sprague, 1995; Mutz, 2002). Since people with whom one has strong personal ties are more influential on one's political behavior (e.g., Bond et al., 2012), the impact of face-to-face discussion might be stronger. Due to these conflicting perspectives, we do not present a directional hypothesis. Yet, we report in the Results section formal tests comparing the effects of face-to-face and online discussion heterogeneity on affective polarization. 


\section{Method}

\section{Data}

We test our hypotheses with three complementary studies. ${ }^{1}$ Study 1 uses cross-sectional survey data from the Digital Democracy Project's (DDP) study of the 2019 Canadian federal election, which was a multi-wave cross-sectional survey of Canadian citizens 18 years or older preceding, during, and after the 2019 Canadian federal election. Our political discussion questions were included in three independent waves of this study fielded from August 28September 5, $2019(N=1,262)$; October 14-20, $2019(N=2,148)$; and October 24-November 4, $2019(N=1,869)$. The non-probability opt-in online samples were provided by Qualtrics.

Sample quotas for Study 1 were set on gender (i.e., male, female), age (i.e., 18/34, 35/54, 55+), region (i.e., Atlantic, Quebec, Ontario, and West), and language (i.e., English, French) to match with 2016 Canadian census population benchmarks. Table S1 of the online supplementary materials shows the comparison of these data to the census across these benchmarks. Our sample compares favorably. In the survey, we asked our respondents: "In federal politics, do you usually think of yourself as a(n)..." We use respondents who indicated their identification with the three major, national parties in Canada: the Liberal Party, the Conservative Party, and the New Democratic Party (NDP), whose supporters comprise $68 \%$ of the respondents $(N=3,596)$.

Study 2 uses data from a two-wave panel survey conducted by the Media Ecosystem Observatory (MEO) on adult Canadian citizens. Our political discussion battery was included in four waves of data collected between March 25 and April 19, $2020(N=9,952)$ from the online sample provider Dynata. Quotas were set in an identical fashion as in Study 1. Approximately

\footnotetext{
${ }^{1}$ The data sets and code necessary to replicate all empirical analyses in this article are available at https://osf.io/vutw4.
} 
half of these individuals were re-contacted between April 24 and May 27, $2020(N=4,910$, of which 3,408 are partisans of the three major parties). Table S1 provides a comparison of the demographic makeup of the re-contacts with the cross-sectional study and with population benchmarks. The use of panel data allows us to minimize the threat of unobserved heterogeneity and selection bias (Mummolo \& Peterson, 2018), though we were only able to include in this study one of our three measures of affective polarization, as elaborated below.

Our fixed effects panel analysis, however, does not allow us to rule out reverse causality: partisan affect may cause heterogeneity rather than the reverse. To shed more light on causal direction, we conducted Study 3 based on questions in MEO surveys fielded from January 19February 1, $2021(N=2,005)$ using the sample provider Dynata. Sampling procedures were identical to Study 2, and Table S1 describes the demographic makeup of respondents in this study. Study 3 follows the two stage least squares (2SLS) approach of Scheufele et al. (2006) to sort out endogenous relationships between political discussion heterogeneity and political participation, but in our case, we are interested in affective polarization. 2SLS allows for the construction of instrumental variables to be used in place of endogenous variables in the second stage estimation. Ideal instruments cause the endogenous variables, only influence the dependent variable through the endogenous variable, and are unrelated to the error term.

\section{Affective Polarization Measures}

As in prior work on affective polarization (e.g., Iyengar et al., 2012), we measure out-party animus in all three studies using 0-100 feeling thermometers. Our respondents were asked, "How do you feel about the political parties? Using a scale from 0-100 where zero means you really dislike the party and one hundred means you really like the party?" We average responses to the Liberal and NDP feeling thermometers for Conservative Party respondents, and use the 
Conservative Party thermometer for Liberal and NDP partisans. We make this coding decision because polarization dynamics in Canada are largely a result of the divergence of the major center-left parties, the Liberals and NDP, from the center-right Conservative Party. For example, Liberal and NDP partisans are increasingly ideologically similar and distinct from Conservative partisans, and affective polarization is largely characterized by increasing animus of Liberal and NDP partisans towards the Conservative Party, and vice versa (Cochrane, 2015; Johnston, 2019).

Traditional feeling thermometers, while informative, have some problems. The 0-100 scale provides artificial precision, while it fails to measure dimensions of affective polarization related to feelings towards out-party supporters by focusing on broad political objects like parties. Thus, in Study 1 and Study 3, we supplement our feeling thermometers with two additional measures of individual-level out-party animus. First, we ask respondents to evaluate the applicability of certain traits to describe party officials or their supporters (Garrett et al., 2014): "Below, we've given a list of words that some people might use to describe [Conservative Party/Liberal Party/NDP] [candidates and elected officials/voters]. For each item, please indicate how well you think it applies to them.” The traits respondents rated were patriotic, intelligent, honest, openminded, generous, hypocritical, selfish, and mean. The response categories for all traits were: extremely well, somewhat well, not very well, and not well at all. We randomized the battery such that some respondents received items that asked them to evaluate party officials, while others received the same questions as they related to voters of those parties. We sum up the responses for the positive and negative words separately and take the difference between them as a measure of net affect toward each party. Again, for a measure of out-party affect, we average responses to the Liberal and NDP measures for Conservative supporters, and use the 
Conservative Party measure for Liberal and NDP partisans. We rescale our measures from 0-100 for comparability with the feeling thermometers.

Second, we evaluate the social distance of our respondents from supporters of the outparty. This is a measure of social alienation that has been treated by scholars as a distinct dimension of affective polarization with different causes and consequences (Druckman \& Levendusky, 2019). We ask our respondents how comfortable they would be having neighbors on their street and close friends that are supporters of each party. Response options for these questions were: not at all comfortable, not too comfortable, somewhat comfortable, and very comfortable. We also ask how upset they would be if their son or daughter married a supporter of each party: not at all upset, not too upset, somewhat upset, and very upset. We sum responses to all three questions for each party and rescale our measures from $0-100$, where 100 is the largest social distance. ${ }^{2}$

In the analyses that follow, we rescale the feeling thermometer and character trait measures so that higher values on all three affective polarization measures indicate higher levels of outparty animus.

\section{Discussion Heterogeneity Measures}

The political communication literature proposes a variety of ways to assess discussion heterogeneity. One important conceptual distinction, suggested by Klofstad et al. (2013), is between heterogeneity based on respondents' perceptions of the partisan leanings of their discussion partners (which they label "partisan disagreement"), and heterogeneity based on respondents' perceptions of how much disagreement is occurring in their network ("general

\footnotetext{
2 The three measures of affective polarization used in Study 1 and Study 3 do not scale together well. The Cronbach's alpha is 0.56 and 0.59 , respectively. In light of this, we estimate models treating each affect measure as a separate outcome.
} 
disagreement"). Here, we include items on both the perceived partisanship of one's discussants and the perceived disagreement in one's network. Although the main analyses presented below combine these items into a single index, we present supplemental analyses where the heterogeneity measure is broken down by type of disagreement.

In line with widely used and well-validated measures of discussion heterogeneity (Hutchens et al., 2018; Scheufele et al., 2004), we construct, in Study 1 and Study 2, an index summarizing respondents' answers to a series of items asking about their discussions with people who have various political characteristics: "Over the past week, did you talk about politics or public affairs [face-to-face/online] with the following people ${ }^{3}$ 1) People whose political views are different from yours; 2) People who support the Liberal Party; 3) People who support the Conservative Party; 4) People with extreme left views; 5) People with extreme right views.” Response categories were: yes, no, or unsure. We created indices of heterogeneity that increment upward for each affirmative response. Respondents who scored above or below five on a $0-10$ left-right scale were not credited with more heterogeneity if they discussed politics with people on the extreme right or left, respectively. Conservative partisans were not credited with discussing politics with Conservative supporters, while Liberal and NDP partisans were not credited with discussing politics with Liberal supporters. ${ }^{4}$

Since the distributions of these heterogeneity indices are highly right-skewed, we create categorical variables for face-to-face and online heterogeneity where ' 0 ' is for respondents with

\footnotetext{
${ }^{3}$ The question wording for Study 2 was "face-to-face or over the phone," owing to its fielding during the COVID-19 pandemic. As we elaborate below, a similar approach was taken in Study 3. ${ }^{4}$ The correlation between the indices for face-to-face and online discussion heterogeneity is $r=$ 0.5 in Study 1 and $r=0.48$ in Study 2. These moderate correlations indicate that while face-toface and online discussion heterogeneity are closely related constructs (as one would expect), they are far from being identical.
} 
a homogeneous discussion network, ' 1 ' is for those who engaged in no discussion according to the frequency measures below, and ' 2 ' is for those with any discussion outside of their partisan or ideological group. Our interest is in the difference between those with homogeneous networks and those with some degree of heterogeneity.

In Study 3, we measure political heterogeneity in a manner similar to Scheufele and his colleagues (2006). We ask respondents, “On a scale from one to ten, where 'one' means never and 'ten' means all the time, how often do you talk to the following groups of people face-toface or over the phone about political issues or candidates?" Options included people whose political views are different from your own, people who support the Conservative Party/Liberal Party, and those with extreme left/right views. We construct a measure of face-to-face discussion heterogeneity by averaging these scales together. ${ }^{5}$ We standardize our face-to-face discussion heterogeneity measure, as well as our three measures of affective polarization, for ease of effect size interpretation.

\section{Control Variables}

Our models account for a variety of confounding factors that could be associated with both heterogeneous discussion and polarization. First, we control for the overall frequency of face-to-face and online discussion, which prior research shows should be controlled for (Eveland \& Hively, 2009), by asking respondents how often they had face-to-face discussion with friends, family, and co-workers. A similar question measured online discussion frequency. Response categories were never, once, a few times, almost every day, daily, don't know. Second, we

\footnotetext{
${ }^{5}$ We omit online discussion heterogeneity from the 2SLS analysis because we are not confident the instruments for discussion heterogeneity (i.e., discussion at work, church, or volunteer organizations) can adequately proxy for this dimension of heterogeneity. Future work should use the 2SLS approach and identify instruments that can be equally suitable for both online and faceto-face discussion heterogeneity.
} 
expect information consumption patterns to be correlated with political discussion. Individuals with a wider breadth of news and social media usage may also have a wider breadth of political discussion, and this information exposure could have implications for out-party affect. We measure news exposure with a logged index of exposure to a list of news outlets in the past week, and social media usage with a logged index of nine social media platforms used in the past week. Third, affective polarization is higher among those who are more interested in politics, and these political sophisticates are likely to have more homogeneous discussions. We control for political interest with a $0-10$ measure where 10 represents those who are very interested in politics generally.

Fourth, individuals with stronger ideological views and partisan attachments are likely to have higher levels of out-party animus and more homogeneous discussion networks. We include a folded 0-10 left-right self-placement scale to measure ideological extremity, and a measure of partisan strength where respondents were asked whether their partisan attachment was "not very strong," "fairly strong," or "very strong." Fifth, we control for ideology and partisanship. There may be asymmetries in out-party animus and discussion heterogeneity that could produce a spurious correlation between discussion and affective polarization. We include binary variables for Conservative and NDP partisanship (reference category = Liberal) and a 0-10 left-right selfplacement scale. ${ }^{6}$ Sixth, we include sociodemographic controls for education, age, gender, language, and region. Finally, whenever relevant, we control for survey wave because we want to ensure temporal dynamics are not confounding our estimates. Descriptions of all measures can be found in Table S2 of the supplementary materials.

\footnotetext{
${ }^{6}$ In our social distance model, we also control for the average social distance towards nonpartisan social groups. General alienation towards society may be associated with both social distance towards out-party supporters and discussion network composition.
} 


\section{Models}

In Study 1, we regress each of our out-party affect measures on the categorical measures of face-to-face and online discussion network heterogeneity and our controls $(X)$ as follows:

$$
\begin{array}{r}
\text { affect }=\alpha+\beta_{1} \text { heterogeneous_facetoface }+\beta_{2} \text { none_facetoface } \\
+\beta_{3} \text { heterogeneous_online }+\beta_{4} \text { none_online }+\beta X+\varepsilon
\end{array}
$$

We include categories for no face-to-face and no online discussion to ensure that our coefficients of interest reflect a comparison between those with some heterogeneous discussion and those whose discussion was entirely homogeneous. To be consistent with $H 1$ and $H 2$, we expect negative significant coefficients on $\beta_{1}$ and $\beta_{3}$, respectively.

Our reliance on covariates to address unobserved heterogeneity in Study 1 leaves us vulnerable to the possibility that our inferences are model dependent. We address this concern in two ways. First, we show that our estimates are robust to different specifications by drawing samples of our coefficients of interest for $20 \%$ of all possible covariate combinations. More information is provided in the supplementary materials (Figures S1-S3). Second, we use matching methods, which ensure greater balance among covariates in the treatment and control groups (Morgan \& Winship, 2015). Full details on our matching procedures, which produce practically identical results as those reported below, can be found in the supplementary materials (Tables S4-S10).

In Study 2, we implement a fixed effects specification to isolate over-time variation in affect and discussion heterogeneity, thereby eliminating the threat posed by time-constant factors and selection bias. We regress the out-party feeling thermometer on the same controls $(X$, minus 
time-constant socio-demographics) and include respondent-level fixed effects $(\mu) .{ }^{7}$ Here, too, negative significant coefficients on $\beta_{1}$ and $\beta_{3}$ will be consistent with $H 1$ and $H 2$, respectively:

$$
\begin{aligned}
\text { affect }_{i, t}=\alpha & +\beta_{1} \text { heterogeneous_facetoface }_{i, t}+\beta_{2} \text { none_facetoface }_{i, t} \\
& +\beta_{1} \text { heterogeneous_online }_{i, t}+\beta_{4} \text { none_online }_{i, t}+\beta X_{i, t}+\mu_{i}+\varepsilon
\end{aligned}
$$

In Study 3, we conduct our 2SLS analysis. Stage one involves the construction of the instruments for discussion heterogeneity using our context discussion measures. Scheufele et al. (2006) argue that there are certain contextual factors that cause political discussion heterogeneity, specifically the amount of political discussion at work, at church, or in nonchurch volunteer organizations. These situations, in effect, impose heterogeneous political discussion on individuals. Importantly, these variables are unlikely to be themselves caused by out-party animus, so we use them to construct an instrument for political discussion heterogeneity. We conduct this analysis only for face-to-face heterogeneity because we are not confident these measures can serve as appropriate instruments for the online context.

Respondents were asked, “On a scale from one to ten, where 'one' means never and 'ten' means all the time, how often do you talk to the following groups of people about political issues or candidates?" Options included people at work, people at your church or place of worship, and people at a nonchurch community/volunteer group. We use these 1-10 scales to create instruments for face-to-face discussion heterogeneity. The instrument for face-to-face discussion heterogeneity is very highly correlated with the endogenous variable $(r=0.75, p<0.001)$.

\footnotetext{
${ }^{7}$ We omit time fixed effects because two-way fixed effects models-in their combination of over-time and cross-sectional variation - are more difficult to interpret (Kropko \& Kubinec, 2020). The short interval between waves also mitigates the threat of time-varying confounders. Either way, a two-way fixed effects model recovers similar estimates, shown in Table S11 of the supplementary materials.
} 
The second stage uses the constructed instrument in place of face-to-face discussion heterogeneity. We include the same controls $(X)$ as in Study 1 but omit partisanship, ideology, partisan strength, and ideological extremity because we have little expectation that they serve as confounds for the instrumental variables. The second-stage equation we estimate is as follows:

$$
\text { affect }=\alpha+\beta_{1} \text { instrument }+\beta X+\varepsilon
$$

\section{Results}

Our model estimates for Study 1 are shown in the first six columns of Table 1. The coefficients for heterogeneous discussion, as noted, can be interpreted as the effect of heterogeneous discussion compared to homogeneous discussion. We find strong support for $\mathrm{HI}$ in Study 1. Respondents who engaged in heterogeneous face-to-face discussion are expected to have out-party feeling thermometer evaluations 2.5 points warmer than those whose discussion occurred in a homogeneous network, which is approximately 0.10 standard deviations on this measure or $5.8 \%$ of the gap between in-party and out-party feeling thermometers $(p<0.05)$. They are also expected to have trait evaluations 1.8 points warmer $(p<0.05)$ and social distance scores 5.4 points lower $(p<0.01)$ than those with homogeneous networks, which are the equivalent of 0.09 and 0.21 standard deviations on these measures, or $7.7 \%$ and $40.2 \%$ of the gaps between in-party and out-party evaluations, respectively. ${ }^{8}$

The results of Study 1 also provide support for $H 2$. Heterogeneous online discussion is associated with less animus on two of our three measures. Respondents who engaged in heterogeneous online discussion have out-party feeling thermometers 3.8 points warmer than those whose discussion occurred in a homogeneous network $(p<0.05)$, which is approximately

\footnotetext{
${ }^{8}$ Respondents were randomly assigned versions of the trait battery about party elites or voters. We find no significant interactive effects (see Table S3).
} 
0.16 standard deviations on this measure or $8.9 \%$ of the gap between in-party and out-party

feeling thermometers. They are also expected to have trait evaluations 2.5 points warmer $(p<$

0.10 ) than those with homogeneous networks, which is the equivalent of 0.13 standard deviations

on this measure or $11 \%$ of the gap between in-party and out-party trait evaluations. There is no

association between online discussion heterogeneity and social distance. ${ }^{9}$

Table 1. OLS Estimation Results (Study 1 and Study 2)

\begin{tabular}{|c|c|c|c|c|c|c|c|c|}
\hline \multirow{3}{*}{ Affective polarization $=$} & \multicolumn{6}{|c|}{ Study 1} & \multirow{2}{*}{\multicolumn{2}{|c|}{$\begin{array}{c}\text { Study } 2 \\
\text { Thermometer }\end{array}$}} \\
\hline & \multicolumn{2}{|c|}{ Thermometer } & \multicolumn{2}{|c|}{ Character Traits } & \multicolumn{2}{|c|}{ Social Distance } & & \\
\hline & Coef. & $S E$ & Coef. & $S E$ & Coef. & $S E$ & Coef. & $\mathrm{SE}$ \\
\hline Heterogeneous Face-to-Face Discussion & $-2.47 * *$ & 1.04 & $-1.75 * *$ & 0.88 & $-5.37 * * *$ & 0.87 & $-2.38 * * *$ & 0.77 \\
\hline No Face-to-Face Discussion & $-5.59 * * *$ & 1.58 & -1.37 & 1.33 & $-4.22 * * *$ & 1.31 & -0.36 & 1.34 \\
\hline Heterogeneous Online Discussion & $-3.83 * *$ & 1.52 & $-2.50 *$ & 1.29 & 1.58 & 1.27 & $-2.80 * * *$ & 0.92 \\
\hline No Online Discussion & $6.11 * * *$ & 2.00 & $3.76^{* *}$ & 1.70 & 0.61 & 1.69 & -0.83 & 1.26 \\
\hline Online Discussion Frequency & $3.10 * * *$ & 0.92 & $3.08 * * *$ & 0.79 & 0.86 & 0.78 & -0.37 & 0.53 \\
\hline Face-to-Face Discussion Frequency & -0.79 & 0.67 & 0.06 & 0.57 & 0.08 & 0.56 & 0.22 & 0.44 \\
\hline News Exposure & $-2.95 * * *$ & 0.59 & $-2.52 * * *$ & 0.50 & $-1.10 * *$ & 0.49 & 1.23 & 0.87 \\
\hline Social Media Exposure & $-1.55 * *$ & 0.72 & -0.55 & 0.61 & $1.36 * *$ & 0.60 & 0.7 & 0.85 \\
\hline Political Interest & 0.33 & 0.23 & $0.50 * * *$ & 0.19 & 0.20 & 0.19 & $-0.62 * *$ & 0.29 \\
\hline Ideological Extremity & $2.88 * * *$ & 0.32 & $2.18 * * *$ & 0.28 & $3.00 * * *$ & 0.27 & 0 & 0.40 \\
\hline Partisan Strength & $5.52 * * *$ & 0.76 & $2.40 * * *$ & 0.65 & $2.81 * * *$ & 0.63 & 0.96 & 0.74 \\
\hline Ideology & $-2.62 * * *$ & 0.21 & $-1.05 * * *$ & 0.18 & $-1.35 * * *$ & 0.17 & $-0.57 * *$ & 0.26 \\
\hline Conservative PID & $5.05 * * *$ & 1.08 & $-2.71 * * *$ & 0.91 & -0.29 & 0.90 & $4.77 * *$ & 1.95 \\
\hline NDP PID & $3.07 * *$ & 1.25 & $1.89 *$ & 1.07 & $3.73 * * *$ & 1.05 & -1.33 & 2.02 \\
\hline Education & $0.55^{* *}$ & 0.22 & 0.30 & 0.19 & $0.43 * *$ & 0.19 & & \\
\hline Age & $0.22 * * *$ & 0.03 & $-0.05 * *$ & 0.03 & -0.03 & 0.02 & & \\
\hline Female & $2.46 * * *$ & 0.91 & -0.81 & 0.78 & 0.39 & 0.76 & & \\
\hline French & 1.46 & 2.65 & -1.45 & 2.25 & -0.44 & 2.21 & & \\
\hline Quebec & 1.25 & 2.89 & $-4.13 *$ & 2.47 & $7.76 * * *$ & 2.42 & & \\
\hline Ontario & 1.05 & 1.82 & -1.55 & 1.55 & $3.52 * *$ & 1.52 & & \\
\hline West & -0.62 & 1.86 & -1.84 & 1.58 & $3.94 * *$ & 1.55 & & \\
\hline Wave 2 & 1.46 & 1.16 & -0.96 & 0.98 & 0.38 & 0.96 & & \\
\hline Wave 3 & $2.95 * *$ & 1.17 & $-3.18 * * *$ & 0.99 & -0.15 & 0.98 & & \\
\hline Social Distance Average & & & & & $0.87 * * *$ & 0.02 & & \\
\hline Constant & $46.31 * * *$ & 5.05 & $52.95 * * *$ & 4.30 & -1.40 & 4.27 & $69.86^{* * *}$ & 3.32 \\
\hline$\overline{R^{2} \text { (within) }}$ & & & & & & & 0.03 & \\
\hline$R^{2}$ & 0.20 & & 0.1 & & 0.48 & & 0.03 & \\
\hline$N$ (groups) & & & & & & & 3,266 & \\
\hline$N$ & 2,648 & & 2,70 & & 2,702 & & 5,579 & \\
\hline
\end{tabular}

$* p<0.1 ; * * p<0.05 ; * * * p<0.01$. Note: reference category for heterogeneous and no discussion is homogeneous discussion; higher values on all dependent variables indicate more affective polarization.

${ }^{9} \mathrm{We}$ also estimate these models using separate components of the heterogeneity index in lieu of a combined measure. The coefficients are presented in Figure S4 of the supplementary materials. The partisan component of this measure is doing the heavy lifting, as expected. 
When comparing the effects of face-to-face and online heterogeneous discussion on affective polarization in Study 1, we find that they mostly do not differ. A Wald test examining the null hypothesis that $\beta_{1}=\beta_{3}$, estimated independently for each outcome, indicates that the face-to-face and online coefficients are indistinguishable from each other in both the feeling thermometer model $(F=0.47, p=0.49)$ and the character traits model $(F=0.20, p=0.66)$. In the social distance model, however, the coefficients are significantly different $(F=17.56, p=$ 0.00 ), which confirms that face-to-face — but not online—discussion predicts greater social distance from out-party supporters.

Next, we present the results of our fixed effects specification for Study 2, which are shown in the final two columns of Table 1. Having a heterogeneous face-to-face discussion network is associated with 2.4 points warmer out-party feeling thermometers over time, compared to having a homogeneous network $(p<0.01)$. This effect is approximately 0.10 standard deviations or $7 \%$ of the gap between in-party and out-party feeling thermometers in this study. Similarly, heterogeneous online discussion is associated with 2.8 warmer out-party feeling thermometers over time, compared to homogeneous discussion $(p<0.01)$, which is approximately 0.12 standard deviations or $8 \%$ of the gap between in-party and out-party feeling thermometers. There is no significant difference between the face-to-face and online coefficients in Study 2 ( $F=0.10$, $p=0.75)$.

One issue with fixed effects models is that the within-unit variation in the treatment (in our case, the within-subject variation in discussion heterogeneity) is often smaller than the overall variation in the independent variable. We thus follow Mummolo and Peterson's (2018) recommendation and use a one standard deviation shift in the residual variation in discussion heterogeneity, net of all other model covariates, as an alternative counterfactual. We find that a 1 
SD change in the within-subject residual variation in heterogeneous discussion (compared to homogeneous discussion) over time is associated with 0.52 points warmer out-party feeling thermometers, for both face-to-face and online discussion contexts.

Finally, Table 2 reports the results of the two-stage least squares (2SLS) model from Study 3. The full estimates can be found in the supplementary materials (Table S12). The estimates for face-to-face discussion heterogeneity reveal that our instrument is consistently associated with lower affective polarization across all three dimensions of affect- - thermometers, character traits, and social distance - with impressive effect sizes. A one standard deviation increase in face-toface discussion heterogeneity is associated with 0.76 and 0.60 standard deviations warmer outparty thermometers and trait scores, respectively $(p<0.001)$, as well as a 0.10 standard deviation reduction in social distance $(p<0.10)$.

Table 2. 2SLS Second-Stage Estimates (Study 3)

\begin{tabular}{lccc}
\hline & DV = Feeling & DV = Character & DV = Social \\
& Thermometer & Traits & Distance \\
\hline Face-to-Face Heterogeneity & $-0.76^{* * *}$ & $-0.60^{* * *}$ & $-0.10^{*}$ \\
& $(0.08)$ & $(0.08)$ & $(0.06)$ \\
\hline
\end{tabular}

$* p<0.1 ; * * p<0.05 ; * * * p<0.01$. Note: standard errors in parentheses. The models control for face-to-face and online discussion frequency, news exposure, social media exposure, political interest, education, age, gender, language, region, and average non-political social distance (social distance models only). Full estimates can be found in Table S12 of the supplementary materials.

There is one key difference in the above results from what we observed in Study 1: the effect sizes are much larger for the feeling thermometer and trait batteries as compared to social distance. This might be a sign that endogeneity is more of a threat on some dimensions of polarization than others. That is, the association between social alienation from out-party members and face-to-face discussion heterogeneity is more driven by the former's effect on the latter, compared to feeling thermometers and trait evaluations. Mapping out the casual 
relationships between different dimensions of affective polarization and types of discussion would be a fruitful avenue for future research.

\section{Discussion}

This study presents robust evidence that heterogeneous political discussion is associated with lower levels of out-party animus. Our results are remarkably consistent. First, we find that heterogeneous discussion predicts lower levels of three indicators of affective polarization. Second, we find that both face-to-face and online discussions have depolarizing effects. Third, our conclusions hold across a variety of samples and methods, including (a) a cross-sectional study complemented by rigorous matching procedures; (b) a two-wave panel study examining over-time effects; and (c) an instrumental variable approach addressing potential endogeneity between discussion and polarization.

Our findings contribute to the rapidly growing affective polarization literature in three main ways. First, we add to vitally important debates on the antecedents of affective polarization (Iyengar et al., 2019). Our results are consistent with the view that political communication effects shape citizens' levels of out-party animus (e.g., Lelkes et al., 2017; Levendusky, 2013). We extend this theoretical perspective by establishing that not only mass-mediated but also interpersonal communication predicts inter-party hostility. The findings of the panel study are especially noteworthy given that the two waves of our panel were separated by only a few weeks. This suggests that a causal effect between political discussion and polarization can occur within a relatively short time frame.

Second, our results join a growing literature suggesting that contact with out-party members can reduce partisan hostility (e.g., Hutchens et al., 2019; Rossiter, 2020). In a recent contribution, Wojcieszak and Warner (2020) have shown that both direct (e.g., having friends 
from the out-party) and indirect interparty contact (e.g., observing a positive interaction between rival partisans) can reduce affective polarization. We extend this perspective by establishing that conversations about politics, both face-to-face and online, are an important form of interparty contact that can reduce partisan hostility. Translating our findings into effective interventions for mitigating polarization might be challenging, however, since many citizens are turned off by partisanship in general, and by partisan disagreement in particular (Klar \& Krupnikov, 2016).

The third contribution of our study is highlighting the importance of measuring affective polarization comprehensively (Druckman \& Levendusky, 2019). We supplement the traditional feeling thermometers with two indicators directly measuring feelings towards out-party supporters. The use of three measures not only increases the generalizability of our conclusions but also allows us to detect two inconsistencies. First, in Study 1, we find that face-to-face discussion heterogeneity predicts less social distance, but online discussion does not. This may be because social distance closely maps onto respondents' face-to-face (i.e., friends, neighbors, and in-laws) rather than online relationships. Second, in Study 3, our effect sizes on social distance are much smaller than the effects on feeling thermometers and character traits, suggesting endogeneity may be more of a concern for the former than the latter two. These tow somewhat divergent results on social distance are in line with Druckman and Levendusky's (2019) claim that thermometers and trait ratings measure general attitudes about parties, whereas social distance taps distinct, more behavioral aspects of affective polarization.

Our study has some limitations worthy of mention. First, our estimated effects might be biased upward because of the effect of affective polarization on discussion heterogeneity. Reciprocal effects, whereby high levels of affective polarization increase discussion with likeminded partners, which in turn increases affective polarization, remain a possibility (Hutchens et 
al., 2019). While we cannot rule out this possibility altogether, our instrumental variable analysis helps mitigate this threat. A second concern is our use of survey-based measures. Such measures may be inaccurate due to limitations in respondents' recall ability or systematically biased due to social desirability. Third, the data for Study 2 and Study 3 were collected during the COVID-19 pandemic, a generational crisis that may have changed, if temporarily, the causal relationships between some important concepts in social science. Perhaps the unprecedented crisis of COVID19 weakened the link between discussion networks and out-party animus. While our data cannot directly address this concern, there is little evidence that affective polarization levels have changed consistently during the pandemic (Boxell et al., 2020a), while various studies document partisan polarization in pandemic response (Pennycook et al., 2020). Polarized politics is business as usual during the pandemic, so we have little grounds to anticipate a weakened link between discussion and polarization. Finally, while Canada has a well-established affective polarization trend (Cochrane, 2015), it remains unclear whether our results hold in countries with different political systems and varying baseline levels of affective polarization.

Future research can extend our results in several ways. First, our observational findings can be complemented by experiments that manipulate discussion heterogeneity —in both face-to-face and online settings - to determine the direction of causality with even more confidence. Second, comparative studies examining the link between discussion heterogeneity and affective polarization across countries can shed further light on the generalizability of the results reported here. Finally, future studies can empirically evaluate the mechanisms of influence theorized here to be responsible for the depolarizing effects of cross-cutting interaction. Such studies could examine whether the information people are exposed to, as well as the salience of their partisan identity, indeed mediate the link between heterogeneous discussion and affective polarization. 


\section{References}

Ahler, D. J., \& Sood, G. (2018). The parties in our heads: Misperceptions about party composition and their consequences. The Journal of Politics, 80(3), 964-981.

Amsalem, E., \& Nir, L. (2021). Does interpersonal discussion increase political knowledge? A meta-analysis. Communication Research, 48(5), 619-641.

Baek, Y. M., Wojcieszak, M., \& Delli Carpini, M. X. (2012). Online versus face-to-face deliberation: Who? Why? What? With what effects? New Media \& Society, 14(3), 363-383.

Barberá, P. (2015). How social media reduces mass political polarization: Evidence from Germany, Spain, and the U.S. Available at http://pablobarbera.com/static/barbera_polarization_APSA.pdf

Bond, R. M., Fariss, C. J., Jones, J. J., Kramer, A. D., Marlow, C., Settle, J. E., \& Fowler, J. H. (2012). A 61-million-person experiment in social influence and political mobilization. Nature, 489(7415), 295-298.

Bond, R. M., Shulman, H. C., \& Gilbert, M. (2018). Does having a political discussion help or hurt intergroup perceptions? Drawing guidance from social identity theory and the contact hypothesis. International Journal of Communication, 12, 4332-4352.

Boxell, L., Conway, J., Druckman, J. \& Gentzkow, M. (2020a). Affective polarization did not increase during the Coronavirus pandemic. Available at https://www.nber.org/papers/w28036

Boxell, L., Gentzkow, M., \& Shapiro, J. M. (2020b). Cross-country trends in affective polarization. Available at https://www.nber.org/papers/w26669

Cochrane, C. (2015). Left and right: The small world of political ideas. Montreal and Kingston: McGill-Queen's University Press. 
Druckman, J. N., \& Levendusky, M. S. (2019). What do we measure when we measure affective polarization? Public Opinion Quarterly, 83(1), 114-122.

Druckman, J. N., Levendusky, M. S., \& McLain, A. (2018). No need to watch: How the effects of partisan media can spread via interpersonal discussions. American Journal of Political Science, 62(1), 99-112.

Eveland, W. P., \& Hively, M. H. (2009). Political discussion frequency, network size, and "heterogeneity" of discussion as predictors of political knowledge and participation. Journal of Communication, 59(2), 205-224.

Garrett, R. K., Gvirsman, S. D., Johnson, B. K., Tsfati, Y., Neo, R., \& Dal, A. (2014). Implications of pro-and counterattitudinal information exposure for affective polarization. Human Communication Research, 40(3), 309-332.

Gidron, N., Adams, J, \& Horne, W. (2020). American affective polarization in comparative perspective. Cambridge: Cambridge University Press.

Healy, A., \& Malhotra, N. (2013). Retrospective voting reconsidered. Annual Review of Political Science, 16, 285-306.

Hetherington, M. J., \& Rudolph, T. J. (2015). Why Washington won't work: Polarization, political trust, and the governing crisis. Chicago, IL: University of Chicago Press.

Huckfeldt R., Johnson, P. E., \& Sprague, J. (2004). Political disagreement: The survival of diverse opinions within communication networks. Cambridge: Cambridge University Press.

Huckfeldt, R., \& Sprague, J. (1995). Citizens, politics, and social communication. New York: Cambridge University Press.

Hutchens, M. J., Eveland, W. P., Morey, A. C., \& Sokhey, A. E. (2018). Evaluating summary measures of heterogeneous political discussion: The critical roles of excluded cases and 
discussion with people holding extreme views. Communication Methods and Measures, 12(4), 276-294.

Hutchens, M. J., Hmielowski, J. D., \& Beam, M. A. (2019). Reinforcing spirals of political discussion and affective polarization. Communication Monographs, 86(3), 357-376.

Iyengar, S., Lelkes, Y., Levendusky, M., Malhotra, N., \& Westwood, S. J. (2019). The origins and consequences of affective polarization in the United States. Annual Review of Political Science, 22, 129-146.

Iyengar, S., Sood, G., \& Lelkes, Y. (2012). Affect, not ideology: A social identity perspective on polarization. Public Opinion Quarterly, 76(3), 405-431.

Johnston, R. (2019). Affective polarization in the Canadian party system 1988-2015. Available at https://www.cpsa-acsp.ca/documents/conference/2019/334.Johnston.pdf

Katz, E., \& Lazarsfeld, P. (1955). Personal influence: The part played by people in the flow of mass communication. New York, NY: The Free Press.

Klar, S. (2014). Partisanship in a social setting. American Journal of Political Science, 58(3), 687-704.

Klar, S., \& Krupnikov, Y. (2016). Independent politics. Cambridge: Cambridge University Press.

Klofstad, C. A., Sokhey, A. E., \& McClurg, S. D. (2013). Disagreeing about disagreement: How conflict in social networks affects political behavior. American Journal of Political Science, 57(1), 120-134.

Kropko, J., \& Kubinec, R (2020). Interpretation and identification of within-unit and crosssectional variation in panel data models. PLOS ONE, 15(4), e0231349.

Lawrence, E., Sides, J., \& Farrell, H. (2010). Self-segregation or deliberation? Blog readership, participation, and polarization in American politics. Perspectives on Politics, 8(1), 141-157. 
Lazarsfeld, P. F., Berelson, B., \& Gaudet, H. (1948). The people's choice: How the voter makes up his mind in a presidential campaign. New York: Columbia University Press.

Lelkes, Y., Sood, G., \& Iyengar, S. (2017). The hostile audience: The effect of access to broadband internet on partisan affect. American Journal of Political Science, 61(1), 5-20.

Levendusky, M. (2013). Partisan media exposure and attitudes toward the opposition. Political Communication, 30(4), 565-581.

Levendusky, M. S., Druckman, J. N., \& McLain, A. (2016). How group discussions create strong attitudes and strong partisans. Research \& Politics, 3(2), 1-6.

Mason, L. (2016). A cross-cutting calm: How social sorting drives affective polarization. Public Opinion Quarterly, 80(S1), 351-377.

Merkley, E. (2020). Polarization eh? Ideological divergence and partisan sorting in the Canadian mass public. Available at https://osf.io/cnzer

Morgan, S. L., \& Winship, C. (2015). Counterfactuals and causal inference: Methods and principles for social research, 2nd ed. Cambridge: Cambridge University Press.

Mummolo, J., \& Peterson, E. (2018). Improving the interpretation of fixed effects regression results. Political Science Research and Methods, 6(4), 829-835.

Mutz, D. C. (2002). Cross-cutting social networks: Testing democratic theory in practice. American Political Science Review, 96(1), 111-126.

Nir, L. (2017). Disagreement in political discussion. In K. Kenski \& K. H. Jamieson (Eds.), The Oxford handbook of political communication (pp. 713-730). New York: Oxford University Press.

Parsons, B. M. (2015). The social identity politics of peer networks. American Politics Research, 43(4), 680-707. 
Pennycook, G., McPhetres, J., Bago, B., and Rand, D. G. (2020). Attitudes about COVID-19 in Canada, the U.K., and the U.S.A.: a novel test of political polarization and motivated reasoning. Available at https://psyarxiv.com/zhjkp/

Rogowski, J. C., \& Sutherland, J. L. (2016). How ideology fuels affective polarization. Political Behavior, 38(2), 485-508.

Rossini, P. (2020). Beyond incivility: Understanding patterns of uncivil and intolerant discourse in online political talk. Advance online publication, Communication Research. doi: $10.1177 / 0093650220921314$

Rossiter, E. (2020). The consequences of interparty conversation on outparty affect and stereotypes. Available at http://erossiter.com/files/conversations.pdf

Scheufele, D. A., Hardy, B. W., Brossard, D., Waismel-Manor, I. S., \& Nisbet, E. (2006). Democracy based on difference: Examining the links between structural heterogeneity, heterogeneity of discussion networks, and democratic citizenship. Journal of Communication, 56(4), 728-753.

Scheufele, D. A., Nisbet, M. C., Brossard, D., \& Nisbet, E. C. (2004). Social structure and citizenship: Examining the impacts of social setting, network heterogeneity, and informational variables on political participation. Political Communication, 21(3), 315-338.

Settle, J. E. (2018). Frenemies: How social media polarizes America. Cambridge: Cambridge University Press.

Sheffer, L. (2020). Partisan in-group bias before and after elections. Advance online publication, Electoral Studies. doi:10.1016/j.electstud.2020.102191

Sinclair, B. (2012). The social citizen: Peer networks and political behavior. Chicago: University of Chicago Press. 
Skytte, R. (2020). Dimensions of elite partisan polarization: Disentangling the effects of incivility and issue polarization. Advance online publication, British Journal of Political Science. doi:10.1017/S0007123419000760

Spears, R. (2011). Group identities: The social identity perspective. In S. J. Schwartz, K. Luyckx, \& V. L. Vignoles (Eds.), Handbook of identity theory and research (pp. 201-224). New York: Springer.

Spears, R., Lea, M., \& Lee, S. (1990). De-individuation and group polarization in computermediated communication. British Journal of Social Psychology, 29(2), 121-134.

Suhay, E. (2015). Explaining group influence: The role of identity and emotion in political conformity and polarization. Political Behavior, 37(1), 221-251.

Sunstein, C. R. (2002). The law of group polarization. Journal of Political Philosophy, 10(2), 175-195.

Tsfati, Y., \& Nir, L. (2017). Frames and reasoning: Two pathways from selective exposure to affective polarization. International Journal of Communication, 11, 301-322.

Tucker, J. A., Guess, A., Barberá, P., Vaccari, C., Siegel, A., Sanovich, S., ... Nyhan, B. (2018). Social media, political polarization, and political disinformation: A review of the scientific literature. Available at http://dx.doi.org/10.2139/ssrn.3144139

Wilson, A. E., Parker, V., \& Feinberg, M. (2020). Polarization in the contemporary political and media landscape. Current Opinion in Behavioral Sciences, 34, 223-228.

Wojcieszak, M. E., \& Warner, B. R. (2020). Can intergroup contact reduce affective polarization? A systematic test of four different forms of intergroup contact. Advance online publication, Political Communication. doi:10.1080/10584609.2020.1760406

Yardi, S., \& Boyd, D. (2010). Dynamic debates: An analysis of group polarization over time on Twitter. Bulletin of Science, Technology \& Society, 30(5), 316-327.

Zaller, J. R. (1992). The nature and origins of mass opinion. Cambridge: Cambridge University Press. 